\title{
Volume-Targeted versus Pressure-Limited Ventilation for Preterm Infants: A Systematic Review and Meta-Analysis
}

\author{
Kevin I. Wheeler ${ }^{a-c}$ Claus Klingenberg ${ }^{a, e, f}$ Colin J. Morley ${ }^{a}$ Peter G. Davis ${ }^{a} d$ \\ ${ }^{a}$ Newborn Services, Royal Women's Hospital, b Monash Institute for Medical Research, 'Murdoch Children's \\ Research Institute, and d Department of Obstetrics and Gynaecology, University of Melbourne, Melbourne, Vic., \\ Australia; ${ }^{e}$ Department of Paediatrics, University Hospital of North Norway, and ${ }^{\mathrm{f}}$ Department of Paediatrics, \\ Institute of Clinical Medicine, University of Tromsø, Tromsø, Norway
}

\section{Key Words}

Ventilation, mechanical $\cdot$ Tidal volume $\cdot$ Bronchopulmonary dysplasia $\cdot$ Systematic review

\begin{abstract}
Background: The causes of bronchopulmonary dysplasia (BPD) are multifactorial. Overdistension of the lung (volutrau$\mathrm{ma}$ ) is considered an important contribution. As an alternative to traditional pressure-limited ventilation (PLV), modern neonatal ventilators offer modes which can target a set tidal volume. Objectives: To determine whether volume-targeted neonatal ventilation, compared with PLV, reduces death or BPD. Methods: We performed a systematic review and metaanalysis using the methodology of the Neonatal Review Group of the Cochrane Collaboration. A comprehensive literature search was undertaken, and data for prespecified outcomes were combined where appropriate using the fixed effects model. Results: Nine trials were eligible. Volume-targeted ventilation resulted in a reduction in: the combined outcome of death or BPD [typical relative risk, RR, 0.73 (95\% confidence interval, 0.57-0.93), numbers needed to treat, NNT, 8 (95\% Cl 5-33)], the incidence of pneumothorax [typical RR 0.46 (95\% Cl 0.25-0.84), NNT 17 (95\% Cl 10-100)], days of ventilation [weighted mean difference 0.8 days (log-transformed data, $p=0.05)]$, hypocarbia $\left(\mathrm{pCO}_{2}<35 \mathrm{~mm} \mathrm{Hg} / 4.7\right.$
\end{abstract}

kPa); [typical RR 0.56 (95\% Cl 0.33-0.96), NNT 4 (95\% Cl 2-25)], and the combined outcome of periventricular leukomalacia or grade 3-4 intraventricular hemorrhage [typical RR 0.48 (95\% Cl 0.28-0.84), NNT 11 (95\% Cl 7-50)]. Conclusions: Compared with PLV, infants ventilated using volume-targeted ventilation had reduced death/BPD, duration of ventilation, pneumothoraces, hypocarbia and periventricular leukomalacia/severe intraventricular hemorrhage. Further studies are needed to assess neurodevelopmental outcomes.

Copyright $\odot 2011$ S. Karger AG, Basel

\section{Introduction}

\section{Rationale}

Volutrauma has been associated with the development of lung injury in neonates [1-7]. Traditional pressurelimited ventilation (PLV) modes use a fixed peak inflating pressure (PIP), but tidal volume delivery varies from inflation to inflation as the baby breathes and the compliance and resistance change. Volume-targeted ventilation (VTV) aims to deliver a target tidal volume with each inflation, and therefore reduce the risk of lung injury from volutrauma.

Previously, studies have reported reductions in tidal volume variation using VTV $[8,9]$, and a meta-analysis

\section{KARGER}

Fax +4161306 1234 E-Mail karger@karger.ch www.karger.com
(C) 2011 S. Karger AG, Base

1661-7800/11/1003-0219\$38.00/0

Accessible online at:

www.karger.com/neo
Dr. Kevin I. Wheeler

Newborn Services, Royal Women's Hospital

Locked Bag 300, Cnr Grattan St/Flemington Road

Parkville, VIC 3052 (Australia)

Tel. +61 8345 3763, E-Mail kevin.wheeler@ thewomens.org.au 
has suggested that VTV compared with PLV reduced the duration of ventilation, rate of pneumothorax and rate of severe intraventricular hemorrhage (IVH) [10].

\section{Objectives}

The aim of this report is to systematically review data from all randomized trials to determine whether ventilation of newborn infants with VTV reduces the risks of mortality or morbidity compared with PLV.

\section{Methods}

Protocol

The protocol for this review was first registered with the Cochrane Collaboration in 2002 [11].

\section{Eligibility}

We included all randomized trials comparing VTV with PLV. We excluded crossover studies, which are only able to assess shortterm outcomes.

\section{Outcomes}

The outcomes measured included death, bronchopulmonary dysplasia (BPD) defined as oxygen treatment or respiratory support at 36 weeks' corrected gestation, air leak, incidence of hypocarbia $\left(\mathrm{pCO}_{2}<35 \mathrm{~mm} \mathrm{Hg} / 4.7 \mathrm{kPa}\right.$ ), duration of ventilation, cranial ultrasound findings and neurodevelopmental outcomes.

\section{Search}

Relevant trials comparing VTV with PLV were identified using the standard search strategy of the Neonatal Review Group of the Cochrane Collaboration. Trials were sought using MEDLINE, CINAHL, and the Cochrane Central Register of Controlled Trials. Articles published before November 2010 were included. Databases were searched using the MeSH terms: 'infant, newborn' and 'respiration, artificial' and the text word 'volume'. No language restrictions were applied. Abstracts published by the Society for Pediatric Research and the European Society for Pediatric Research were hand searched. In addition to cross-referencing previous reviews, expert informants were contacted and newer additional resources such as clinicaltrials.gov and the WHO international clinical trials search portal were searched. Two authors (K.W. and C.K.) independently conducted the search and evaluated articles for eligibility, methodological quality and risk of bias.

\section{Data Collection}

For each trial, information was sought regarding the method of randomization, stratification, concealment strategies and completeness of reporting. Data for duration of ventilation, incidence of BPD and neurodevelopmental outcomes were standardized as outcomes in survivors. If appropriate, trial authors were contacted to clarify or obtain additional prospectively collected data, including combined outcomes for death or BPD, severe IVH or periventricular leukomalacia (PVL) and death or neurodevelopmental impairment. For trials with short intervention periods $(<72 \mathrm{~h})$, we included only data for outcomes occurring during the intervention period. For longer trials, we included all relevant outcomes.

Summary Measures and Synthesis of Results

Meta-analysis of the included trials was performed using RevMan 5 (v5.0, Copenhagen, The Nordic Cochrane Centre, The Cochrane Collaboration 2008). Relative risks were calculated for binary outcomes; weighted mean differences (WMD) for continuous outcomes. The fixed effect model was used. For statistically significant results $(\mathrm{p}<0.05)$, numbers needed to treat $(\mathrm{NNT})$, risk differences and 95\% confidence intervals were calculated according to the methods of the Cochrane Handbook for Systematic Review of Interventions [12]. Evaluation of heterogeneity was conducted using the $\mathrm{I}^{2}$ statistic to determine the suitability of pooling results. Meta-analysis of skewed continuous data was repeated using data transformed to approximate a normal distribution.

The full results of this review are published in the Cochrane Database of Systematic Reviews [13]. The review included both parallel randomized controlled trials (RCTs) and crossover studies, and updates the previous review published 5 years previously [10]. This publication aims to report the main outcomes of the meta-analysis in the format of a journal article, as encouraged by The Lancet [14]. In this extract, we report the clinically important outcomes of the RCTs only.

\section{Results}

\section{Study Selection}

A flowchart of the studies screened is shown in figure 1. Nine trials (ten publications) met criteria for inclusion in this review $[8,15-23]$. Consensus was reached regarding all included studies and outcomes.

\section{Study Characteristics}

The characteristics of infants included varied between the trials (table 1). All trials commenced within $72 \mathrm{~h}$ of birth. Two trials (74 infants) were short (Cheema intervention until first blood gas [17], Nafday intervention for $24 \mathrm{~h} \mathrm{[20]),} \mathrm{and} \mathrm{for} \mathrm{these} \mathrm{trials,} \mathrm{we} \mathrm{only} \mathrm{included} \mathrm{outcomes}$ occurring during the intervention period.

\section{VTV Modes}

The included trials used a variety of ventilators and modes. Three trials used the Siemens Servo 300 pressure-regulated volume control (PRVC) mode, which measures tidal volume using a flow sensor at the ventilator. The ventilator uses a decelerating flow waveform and adjusts PIP in response to inspired tidal volume. Two trials used volume control (VC) mode with the VIP Bird ventilator. This mode measures tidal volume using a flow sensor at the ventilator, and controls the volume entering the inspiratory limb of the ventilator in real- 
Fig. 1. Flow chart showing the number of studies.

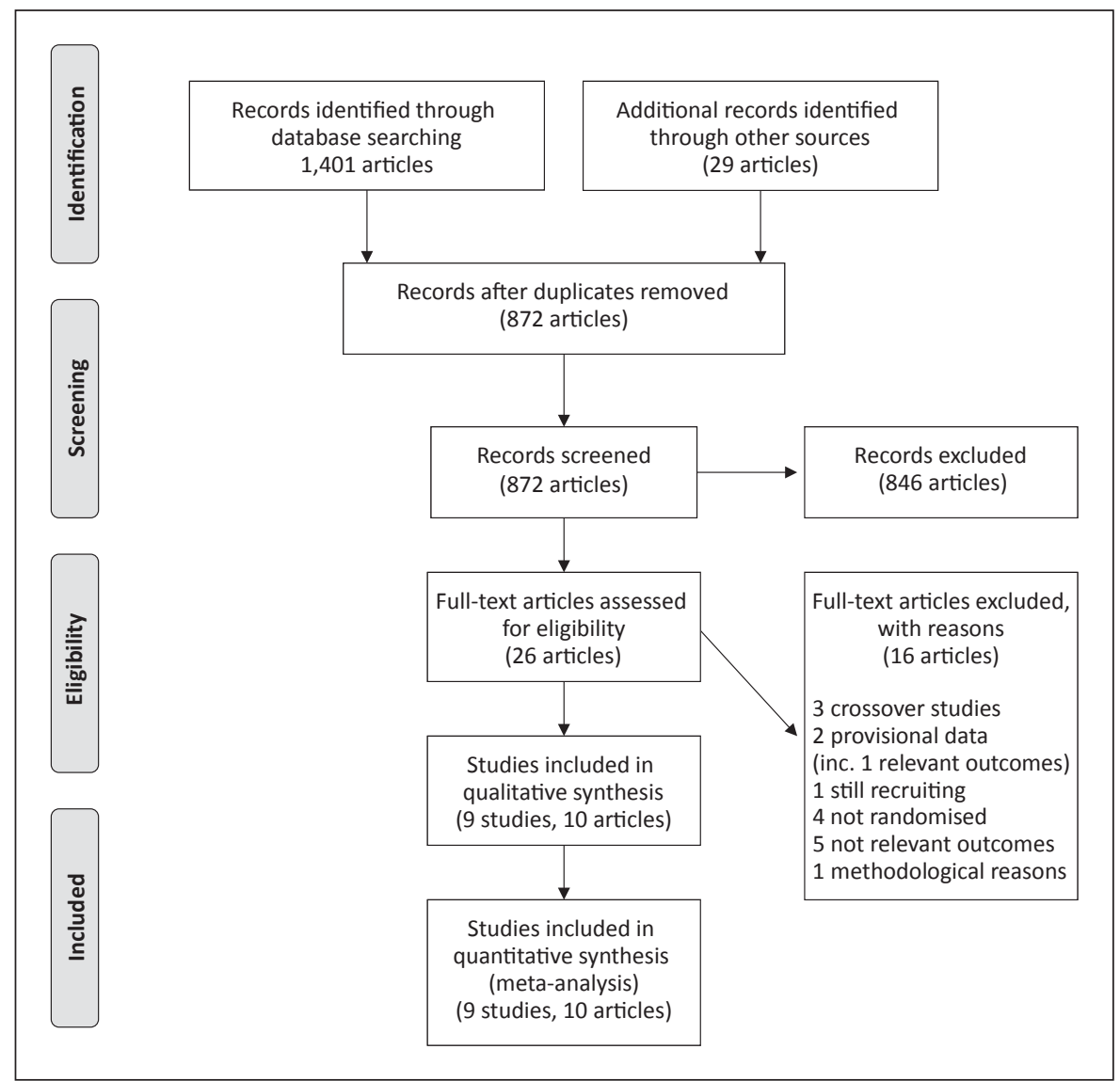

time. Four trials used the Dräger Babylog 8000+ volume guarantee (VG) mode, which measures tidal volume using a flow sensor positioned at the Wye connector and adjusts PIP in the range response to expired tidal volume.

\section{Trial Methodology, Risk of Bias and 'Hybrid' Studies}

All included trials used random allocation of participants, generally by sealed envelopes. None concealed the intervention from the clinical team. Follow-up was adequate in all trials, including those which included outcomes after discharge from hospital.

The VTV modes varied between trials and include Siemens Servo PRVC, VIP Bird VC and Dräger Babylog 8000plus VG. PRVC and VC are both modes which control the inspired tidal volume entering the ventilator circuit. VG is a mode which targets the tidal volume at the Wye connector. Differences in these approaches are discussed further in the full review [13] and by other authors $[17,24,25]$. Five trials had further differences between the groups other than a 'pure' comparison between PLV and
VTV. We considered these as 'hybrid' studies (table 1). These differences included the use of different ventilators in the two groups, different modes (e.g. synchronized intermittent ventilation versus PRVC), and different triggers for inspiration and/or expiration.

In some studies, the weaning strategies in VTV differed from PLV, and some infants crossed between groups. These additional differences have the potential to introduce bias and are described in table 1 . In the full review published by the Cochrane Collaboration [13], we performed subgroup analysis for the 'pure' and 'hybrid' studies. The full results are not included in this paper; however, we discuss where differences were identified in those subgroup analyses.

In the study of Piotrowski et al. [21], the participants appeared to have a non-uniform distribution of severity of lung disease despite randomization. These infants may have been at unequal risk at inception. The authors performed a post hoc adjustment for initial oxygen concentration $\left(\mathrm{FiO}_{2}\right)$ as a proxy for initial disease severity. We included the non-adjusted data in this meta-analysis. 
Table 1. Types of subjects and characteristics of studies

\begin{tabular}{|c|c|c|c|c|c|c|c|}
\hline $\begin{array}{l}\text { First author } \\
\text { and year }\end{array}$ & $\begin{array}{l}\text { Number of subjects, } \\
\text { inclusion criteria }\end{array}$ & $\begin{array}{l}\text { VTV group } \\
\text { mode (ventilator) }\end{array}$ & $\begin{array}{l}\text { PLV group } \\
\text { mode (ventilator) }\end{array}$ & Duration & $\begin{array}{l}\text { Hybrid } \\
\text { interventions }\end{array}$ & Comments & $\begin{array}{l}\text { Outcomes used } \\
\text { in meta-analysis } \\
\text { (including } \\
\text { supplemental data) }\end{array}$ \\
\hline $\begin{array}{l}\text { Piotrowski } \\
1997[15]\end{array}$ & $\begin{array}{l}57 \text { infants; }<2,500 \mathrm{~g}, \\
<72 \mathrm{~h} \text { old, } \\
\text { ventilated for lung } \\
\text { disease }\end{array}$ & $\begin{array}{l}\text { PRVC } \\
\text { (Siemens } \\
\text { Servo 300) }\end{array}$ & $\begin{array}{l}\text { Non-synchronized } \\
\text { IMV } \\
\text { (several ventilators) }\end{array}$ & $\begin{array}{l}\text { Until } \\
\text { extubation }\end{array}$ & $\begin{array}{l}\text { Different use of } \\
\text { trigger settings } \\
\text { and ventilators in } \\
\text { VTV and PLV } \\
\text { groups }\end{array}$ & & $\begin{array}{l}\text { Death in hospital, } \\
\text { air leak, IVH, } \\
\text { duration of } \\
\text { ventilation }\end{array}$ \\
\hline $\begin{array}{l}\text { Sinha } \\
1997[22]\end{array}$ & $\begin{array}{l}50 \text { infants; }>1,200 \mathrm{~g} \text {, } \\
\text { ventilated for RDS }\end{array}$ & $\begin{array}{l}\text { AC+VC } \\
\text { (VIP Bird Infant/ } \\
\text { Paediatric) }\end{array}$ & $\begin{array}{l}\text { AC } \\
\text { (VIP Bird) }\end{array}$ & $\begin{array}{l}\text { Until } \\
\text { weaning from } \\
\text { ventilator }\end{array}$ & $\begin{array}{l}\text { Different use of } \\
\text { trigger technique } \\
\text { in VTV (pressure } \\
\text { triggered) and } \\
\text { PLV (flow } \\
\text { triggered) groups }\end{array}$ & & $\begin{array}{l}\text { Death in hospital, } \\
\text { severe IVH or PVL } \\
\text { (not reported } \\
\text { separately), BPD, } \\
\text { pneumothorax }\end{array}$ \\
\hline $\begin{array}{l}\text { Lista } \\
2004 \text { [19] }\end{array}$ & $\begin{array}{l}53 \text { infants; GA } 25- \\
32 \text { weeks, antenatal } \\
\text { steroids, ventilated } \\
\text { at }<24 \text { h old, post } \\
\text { surfactant }\end{array}$ & $\begin{array}{l}\text { PSV+VG } \\
\text { (Dräger Babylog } \\
8000+\text { ) }\end{array}$ & $\begin{array}{l}\text { PSV } \\
\text { (Dräger Babylog } \\
8000+\text { ) }\end{array}$ & $\begin{array}{l}\text { Until } \\
\text { extubation }\end{array}$ & & & $\begin{array}{l}\text { Death in hospital, } \\
\text { BPD, IVH, PVL, } \\
\text { PIE, pneumothorax }\end{array}$ \\
\hline $\begin{array}{l}\text { Keszler } \\
2004[8]\end{array}$ & $\begin{array}{l}18 \text { infants, GA }<34 \\
\text { weeks, }<6 \text { h old, } \\
\text { ventilated for RDS }\end{array}$ & $\begin{array}{l}\text { AC+VG } \\
\text { (Dräger Babylog } \\
8000+)\end{array}$ & $\begin{array}{l}\text { AC } \\
\text { (Dräger Babylog } \\
8000+\text { ) }\end{array}$ & $\begin{array}{l}72 \text { h or until } \\
\text { extubation }\end{array}$ & & & $\begin{array}{l}\text { Death in hospital, } \\
\text { hypocarbia } \\
\text { pneumothorax, } \\
\text { PIE, PVL, IVH }\end{array}$ \\
\hline $\begin{array}{l}\text { Nafday } \\
2005[20]\end{array}$ & $\begin{array}{l}34 \text { infants; }<1,500 \mathrm{~g}, \\
<12 \mathrm{~h} \text { old, } \\
\text { pre-surfactant, } \\
\text { ventilated for RDS }\end{array}$ & $\begin{array}{l}\text { PSV+VG } \\
\text { (Dräger Babylog } \\
8000+\text { ) }\end{array}$ & $\begin{array}{l}\text { SIMV } \\
\text { (Dräger Babylog } \\
8000+\text { ) }\end{array}$ & $\begin{array}{l}24 \mathrm{~h} \text { from } \\
\text { enrolment }\end{array}$ & $\begin{array}{l}\text { Different trigger } \\
\text { modes in VTV } \\
\text { and PLV groups }\end{array}$ & & $\begin{array}{l}\text { Death before } \\
\text { discharge, BPD, } \\
\text { IVH, air leak }\end{array}$ \\
\hline $\begin{array}{l}\text { D’Angio } \\
2005[18]\end{array}$ & $\begin{array}{l}213 \text { infants; } 500- \\
1,249 \text { g, GA } \geq 24 \\
\text { weeks, ventilated }\end{array}$ & $\begin{array}{l}\text { PRVC } \\
\text { (Siemens } \\
\text { Servo 300) }\end{array}$ & $\begin{array}{l}\text { SIMV } \\
\text { (VIP Bird) }\end{array}$ & $\begin{array}{l}\text { Until extubated } \\
\text { or failed mode }\end{array}$ & $\begin{array}{l}\text { Different trigger } \\
\text { modes in VTV } \\
\text { and PLV groups }\end{array}$ & & $\begin{array}{l}\mathrm{PaCO}_{2} \text {, death } \\
\text { before discharge, } \\
\text { age at final } \\
\text { extubation, } \\
\text { pneumothorax, } \\
\mathrm{PIE}, \mathrm{IVH}, \mathrm{PVL} \text {, } \\
\mathrm{BPD} \text {, and home } \mathrm{O}_{2}\end{array}$ \\
\hline $\begin{array}{l}\text { Singh } \\
2006 \text { and } \\
2009 \\
{[16,23]}\end{array}$ & $\begin{array}{l}109 \text { infants; } 600- \\
1,500 \text { g, GA } 24-31 \\
\text { weeks, ventilated } \\
\text { for RDS }\end{array}$ & $\begin{array}{l}\text { VC } \\
\text { (VIP Bird) }\end{array}$ & $\begin{array}{l}\text { PLV } \\
\text { (VIP Bird) }\end{array}$ & $\begin{array}{l}\text { Until } \\
\text { weaning from } \\
\text { ventilator }\end{array}$ & & $\begin{array}{l}\text { VTV group weaned } \\
\text { using SIMV. } \\
94 \text { infants surviving } \\
\text { to discharge, } 3 \text { died. } \\
\text { Follow-up reported } \\
\text { data on } 85 \text { of } 91 \\
\text { eligible infants at } \\
\text { median } 22 \text { months }\end{array}$ & $\begin{array}{l}\text { Total duration of } \\
\text { mechanical } \\
\text { ventilation, death } \\
\text { before discharge, } \\
\text { BPD, IVH } \\
\text { Follow up: home } \\
\text { oxygen }\end{array}$ \\
\hline $\begin{array}{l}\text { Cheema } \\
2007[17]\end{array}$ & $\begin{array}{l}40 \text { infants; GA }<34 \\
\text { weeks ventilated for } \\
\text { RDS }\end{array}$ & $\begin{array}{l}\text { AC+VG } \\
\text { (Dräger Babylog } \\
8000+\text { ) }\end{array}$ & $\begin{array}{l}\text { AC } \\
\text { (Dräger Babylog } \\
8000+\text { ) }\end{array}$ & $\begin{array}{l}\text { Until first blood } \\
\text { gas (median } \\
95 \text { min) }\end{array}$ & & & Hypocarbia, $\mathrm{FiO}_{2}$ \\
\hline $\begin{array}{l}\text { Piotrowski } \\
2007[21]\end{array}$ & $\begin{array}{l}56 \text { infants; GA } 24- \\
34 \text { weeks, ventilated } \\
\geq 24 \text { h for RDS }\end{array}$ & $\begin{array}{l}\text { PRVC } \\
\text { (Siemens } \\
\text { Servo 300) }\end{array}$ & $\begin{array}{l}\text { SIMV (Various } \\
\text { ventilators) }\end{array}$ & $\begin{array}{l}\text { Until } \\
\text { extubation }\end{array}$ & $\begin{array}{l}\text { Different trigger } \\
\text { modes and } \\
\text { ventilators in } \\
\text { VTV and PLV } \\
\text { groups }\end{array}$ & $\begin{array}{l}\text { Different baseline } \\
\text { characteristics. } \\
\text { Unadjusted data } \\
\text { have been used for } \\
\text { meta-analysis }\end{array}$ & $\begin{array}{l}\text { Time to extubation, } \\
\text { air leak, IVH }\end{array}$ \\
\hline
\end{tabular}

$\mathrm{AC}=$ Assist control; $\mathrm{BPD}=$ bronchopulmonary dysplasia; $\mathrm{GA}=$ gestational age; IMV = intermittent mandatory ventilation; IVH = intraventricular hemorrhage; $\mathrm{PC}=$ pressure control; PIE = pulmonary interstitial emphysema; $\mathrm{PLV}=$ pressure-limited ventilation; $\mathrm{PRVC}=$ pressure-regulated volume control; PSV = pressure support ventilation; $\mathrm{PVL}=$ periventricular leukomalacia; $\mathrm{RDS}$ = respiratory distress syndrome; SIMV = synchronized intermittent mandatory ventilation; $\mathrm{VC}=$ volume control; VG = volume guarantee; VTV = volume-targeted ventilation. 


\section{Results of Meta-Analysis}

Outcomes Occurring during Mechanical Ventilation

Relevant outcomes were reported by up to eight trials (fig. 2; table 2). VTV significantly reduced the risk of pneumothorax $(\mathrm{NNT}=17)$, incidence of hypocarbia $(\mathrm{NNT}=4)$ and duration of ventilation $(\mathrm{WMD}=-2.4$ days). Further analysis, taking into consideration the skewed duration of ventilation, reduced this difference to -0.8 days $(p=0.05)$. No statistically significant differences were observed in the risk of pulmonary interstitial emphysema or any air leak, or in $\mathrm{FiO}_{2}$.

\section{Outcomes during the Primary Hospital Admission}

Relevant outcomes were reported by up to seven trials. VTV significantly reduced the combined rates of death or BPD $(\mathrm{NNT}=8)$, and severe IVH (grade 3 or 4 ) or PVL $(\mathrm{NNT}=11)$. There was a borderline reduction in BPD alone $(\mathrm{p}=0.05)$. No statistically significant difference was observed in the risk of death before discharge, severe IVH, PVL, or oxygen treatment at discharge.

\section{Follow-Up Outcomes}

These were available for two trials, although neither was powered for follow-up outcomes. Meta-analysis did not identify any significant difference between VTV and PLV for severe neurodevelopmental impairment, or the combined outcome of severe neurodevelopmental impairment or death.

\section{Statistical Heterogeneity}

There was no evidence of statistical heterogeneity (all $I^{2}$ statistics for all outcomes were $<40 \%$ ), except for the duration of ventilation, any IVH and grade 3-4 IVH. Caution is advised in the interpretation of these results.

\section{Discussion}

\section{Main Findings}

In this systematic review of VTV compared with PLV in preterm neonates, we identified nine trials recruiting 630 infants. The majority of important outcomes (death, BPD and cranial ultrasound findings) were calculated from seven trials which included 556 patients. Some outcome data used in this review are different to the published data of the original trials due to differences in the definitions of the numerators and denominators.

The use of VTV was associated with a significant reduction in the combined outcomes of death or BPD, and of grade 3-4 IVH or PVL. There were reductions in rates of hypocarbia and pneumothorax. The reduction in BPD alone was of borderline statistical significance. A statistically significant reduction in duration of ventilation was suggested by meta-analysis; however, this result should be interpreted with caution because of the skewed data and heterogeneity, particularly within the hybrid trials. We did not identify an increase in any adverse outcomes associated with the use of VTV compared with PLV.

No studies were powered to detect differences in neurodevelopmental outcomes at follow-up, and meta-analysis of the two trials does not identify any significant differences between groups. We urge researchers to collect and report long-term outcome data on all infants enrolled in trials comparing VTV with PLV.

\section{Limitations and Generalizability}

We performed this systematic review and meta-analysis using the standard methods of the Cochrane Collaboration [12]. An important protection against selection bias was the publication of a protocol in the Cochrane Library in 2002 [11] and the use of 2 reviewers who searched for and appraised studies separately. To protect against the risk of publication bias, we search trial registries, conference abstracts and approached expert informants. Because some of these studies compared more than one intervention (e.g. using different ventilators in the VTV and PLV groups), we performed a post hoc subgroup analysis of pure versus hybrid studies to reduce the risk that these studies would bias metaanalysis.

In clinical practice, contributors to mortality and BPD complex are multifactorial [26]. A single well-designed RCT, adequately powered for follow-up outcomes, and with uniform management for all clinical issues would be able to examine these important questions. The challenges of implementing such a trial across multiple centers are considerable, and include the number of patients and centers necessary, and maintaining adequate competence and uniformity of management in both PLV and VTV and maintaining a consistency in neonatal management [27]. We are aware that many clinicians have passed equipoise, and the introduction of such a trial may be difficult in units which have already adopted VTV as standard practice [28].

The studies included in this systematic review are diverse in terms of types of infants enrolled, types of ventilators used, and times at which studies were conducted. Experts have compared outcomes from single large RCTs versus meta-analyses of smaller trials $[29,30]$. Each ap- 


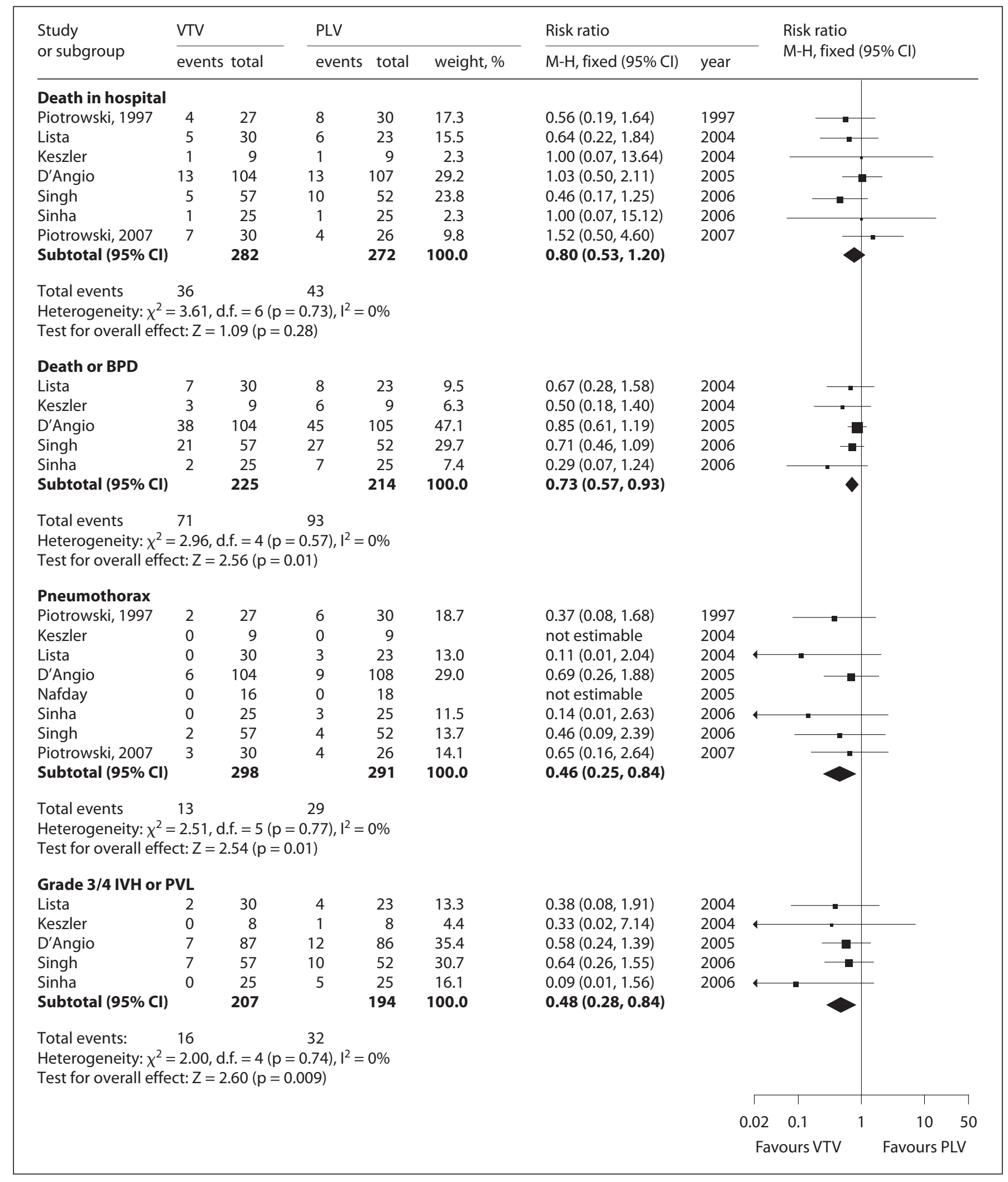

Fig. 2. Forest plot showing relative risk and $95 \%$ confidence intervals for meta-analysis of outcomes occurring during period of ventilation, before discharge, and after discharge. 
Table 2. Meta-analysis of selected outcomes

\begin{tabular}{|c|c|c|c|c|c|c|c|c|}
\hline Outcome & Studies & Patients & \multicolumn{2}{|c|}{ Meta-analysis } & $95 \%$ CI & $\mathrm{p}$ value & Favors & NNT \\
\hline \multicolumn{9}{|l|}{ Ventilation } \\
\hline Hypocarbia & 2 & 58 & $\mathrm{RR}$ & 0.56 & $0.33-0.96$ & 0.04 & VTV & 4 \\
\hline Pneumothorax & 8 & 589 & $\mathrm{RR}$ & 0.46 & $0.25-0.84$ & 0.01 & VTV & 17 \\
\hline PIE & 6 & 430 & $\mathrm{RR}$ & 1.21 & $0.63-2.3$ & 0.57 & & \\
\hline Any pneumothorax or PIE & 5 & 374 & $\mathrm{RR}$ & 0.79 & $0.44-1.43$ & 0.44 & & \\
\hline Duration of ventilation (raw data) & 6 & 431 & WMD & -2.36 days & -3.9 to 0.83 & $<0.01$ & VTV & \\
\hline Duration of ventilation (log-transformed data) & 5 & 381 & WMD & $-0.08 \log$ days $(\approx-0.8$ days $)$ & $-0.16-0$ & 0.05 & VTV & \\
\hline \multicolumn{9}{|l|}{ Primary admission } \\
\hline BPD (36 weeks) & 5 & 413 & RR & 0.73 & $0.53-1$ & 0.05 & & \\
\hline Death before discharge & 7 & 554 & RR & 0.8 & $0.53-1.2$ & 0.28 & & \\
\hline Death or BPD (36 weeks) & 5 & 439 & $\mathrm{RR}$ & 0.73 & $0.57-0.93$ & 0.01 & VTV & 8 \\
\hline Severe IVH & 6 & 494 & $\mathrm{RR}$ & 0.71 & $0.45-1.11$ & 0.13 & & \\
\hline PVL & 4 & 351 & $\mathrm{RR}$ & 0.41 & $0.15-1.16$ & 0.09 & & \\
\hline PVL or severe IVH & 5 & 401 & $\mathrm{RR}$ & 0.48 & $0.28-0.84$ & $<0.01$ & VTV & 11 \\
\hline Oxygen at discharge & 2 & 270 & $\mathrm{RR}$ & 0.64 & $0.3-1.36$ & 0.24 & & \\
\hline \multicolumn{9}{|l|}{ Follow-up } \\
\hline Severe neurodevelopmental impairment & 2 & 213 & $\mathrm{RR}$ & 0.86 & $0.47-1.59$ & 0.63 & & \\
\hline Death or severe neurodevelopmental impairment & 1 & 109 & $\mathrm{RR}$ & 0.54 & $0.27-1.06$ & 0.07 & & \\
\hline
\end{tabular}

proach has its advantages. The consistency of the results across most important outcomes assessed in this review, in spite of the variations between the trials, suggests that the benefits of VTV are robust and may be generalized across many settings.

\section{Implications for Clinical Practice}

Recent surveys of ventilator practice in European and Australasian neonatal units show large variations in the uptake of VTV, spanning from $\approx 10$ to $60 \%[28,31,32]$. Those using VTV cited a reduction in BPD as their main motivation. Those not using VTV cited a lack of evidence [28]. This review adds to the body of evidence supporting the safety and efficacy of VTV. Although data are lacking regarding neurodevelopmental outcomes, the reduction in the combined outcome of death and BPD is important. It is plausible that VTV, by reducing variations in tidal volume $[8,33,34]$, may contribute to a reduction in volutrauma and lung injury. Additionally, by improving the stability of blood gas parameters and reducing hypocarbia $[8,17]$, VTV may stabilize cerebral perfusion and contribute to the reduction in neonatal brain injury [35-37].

\section{Future Research}

Future research needs to focus on neurodevelopmental and respiratory outcomes in childhood, and identifying the optimal methods of applying VTV. Clinical prac- tice varies between neonatal units [28], and the optimum modes and settings for VTV are unknown, including the 'best' target tidal volume and how tightly this should be maintained. Not all current VTV modes are represented in this review, and data were not suitable for a robust subgroup analysis by mode of ventilation, e.g PRVC versus VG. Studies are needed which compare different ventilators and their VTV modes.

\section{Other Considerations}

Ventilator manufacturers can assist clinicians and researchers by making more detailed information available about how their VTV algorithms work. Additionally, manufacturers can assist the infants and their clinicians by incorporating evidence-based improvements to their VTV algorithms to current and new ventilators.

VTV targets the tidal volume delivered to the whole lung. The regional distribution of tidal ventilation may vary throughout the lung in nonhomogenous lung disease. Neither VTV nor PLV can eliminate the risk of regional lung injury from local volutrauma or shear stress, and strategies to manage local variations in lung mechanics may also be important.

The studies included in this review were conducted by researchers with expertise in VTV. We encourage units planning to use VTV to manage this process of change, including education and in-servicing of clinical staff. 


\section{Conclusions}

The use of VTV is associated with important clinical benefits: reductions in the combined outcomes of death/ $\mathrm{BPD}$, incidence of hypocarbia, pneumothorax, duration of ventilation, and the combined outcome of PVL/severe IVH. VTV was not associated with any increase in adverse outcomes.

Further research and development is needed to refine and compare VTV modes and clinical strategies. Insufficient infants have been followed up to assess neurodevelopmental outcomes, and more follow-up data would provide important information about the safety and efficacy of VTV.

\section{Acknowledgements}

We thank the following authors who provided supplementary data included in the meta-analysis: Carl D'Angio, Martin Keszler, Gianluca Lista, Suhas Nafday, Andrez Piotrowski, Ajay Sinha and Sunil Sinha.
We also acknowledge the assistance of Roberto Chiletti and Hania Czerwinska who assisted with translating articles published in Italian and Polish.

K.I.W. is supported in part by a Royal Women's Hospital Postgraduate Research Degree Scholarship and Monash International Postgraduate Research Scholarship. P.G.D. is supported in part by an Australian National Health and Medical Research Council Practitioner Fellowship. The research was funded by Australian National Health and Medical Research Council Program Grant No. 384100.

This review is published as a Cochrane review in The Cochrane Library as Wheeler $\mathrm{K}$, Klingenberg $\mathrm{C}$, McCallion N, Morley CJ, Davis PG: Volume-targeted versus pressure-limited ventilation in the neonate. Cochrane Database Syst Rev 2010; CD003666.

\section{Disclosure Statement}

C.J.M. has provided advice to Dräger Medical. This company had no influence on study design, analyses, reporting or manuscript preparation.

\section{References}

1 Dreyfuss D, Saumon G: Role of tidal volume, FRC, and end-inspiratory volume in the development of pulmonary edema following mechanical ventilation. Am Rev Respir Dis 1993;148:1194-1203.

-2 Dreyfuss D, Saumon G: Ventilator-induced lung injury: lessons from experimental studies. Am J Respir Crit Care Med 1998;157: 294-323.

-3 Hernandez LA, Peevy KJ, Moise AA, Parker JC: Chest wall restriction limits high airway pressure-induced lung injury in young rabbits. J Appl Physiol 1989;66:2364-2368.

-4 Bjorklund LJ, Ingimarsson J, Curstedt T, John J, Robertson B, Werner O, Vilstrup CT: Manual ventilation with a few large breaths at birth compromises the therapeutic effect of subsequent surfactant replacement in immature lambs. Pediatr Res 1997;42:348-355.

-5 Clark RH, Gerstmann DR, Jobe AH, Moffitt ST, Slutsky AS, Yoder BA: Lung injury in neonates: causes, strategies for prevention, and long-term consequences. J Pediatr 2001;139: $478-486$

6 Slutsky AS, Kamm RD, Rossing TH, Loring $\mathrm{SH}$, Lehr J, Shapiro AH, Ingram RH Jr, Drazen JM: Effects of frequency, tidal volume, and lung volume on $\mathrm{CO}_{2}$ elimination in dogs by high frequency $(2-30 \mathrm{~Hz})$, low tidal volume ventilation. J Clin Invest 1981;68:14751484.
7 Muscedere JG, Mullen JB, Gan K, Slutsky AS: Tidal ventilation at low airway pressures can augment lung injury. Am J Respir Crit Care Med 1994;149:1327-1334.

8 Keszler M, Abubakar K: Volume guarantee: stability of tidal volume and incidence of hypocarbia. Pediatr Pulmonol 2004;38:240245.

9 Swamy R, Gupta S, Sing J, Donn SM, Sinha SK: Tidal volume delivery and peak inspiratory pressure in babies receiving volume targeted or time-cycled, pressure limited ventilation: a randomized controlled trial. J Neonatal Perinatal Med 2008;4:239-243.

10 McCallion N, Davis PG, Morley CJ: Volumetargeted versus pressure-limited ventilation in the neonate. Cochrane Database Syst Rev 2005;CD003666.

11 McCallion N, Davies P, Morley CJ: Volumetargeted versus pressure-limited ventilation in the neonate. (Protocol). Cochrane Database Syst Rev 2002.

12 Higgins J, Green S: Cochrane Handbook for Systematic Reviews of Interventions, Version 5.0.2 (updated September 2009). The Cochrane Collaboration, 2009. Available from www.cochrane-handbook.org, 2010.

13 Wheeler KI, Klingenberg C, McCallion N, Morley CJ, Davis PG: Volume-targeted versus pressure-limited ventilation in the neonate. Cochrane Database Syst Rev 2010;CD003666.
14 Clarke M, Horton R: Bringing it all together: Lancet-Cochrane collaborate on systematic reviews. Lancet 2001;357:1728.

15 Piotrowski A, Sobala W, Kawczynski P: Patient-initiated, pressure-regulated, volumecontrolled ventilation compared with intermittent mandatory ventilation in neonates: a prospective, randomised study. Intensive Care Med 1997;23:975-981.

16 Singh J, Sinha SK, Alsop E, Gupta S, Mishra A, Donn SM: Long term follow-up of very low birthweight infants from a neonatal volume versus pressure mechanical ventilation trial. Arch Dis Child Fetal Neonatal Ed 2009; 94:F360-F362.

17 Cheema IU, Sinha AK, Kempley ST, Ahluwalia JS: Impact of volume guarantee ventilation on arterial carbon dioxide tension in newborn infants: a randomised controlled trial. Early Hum Dev 2007;83:183-189.

-18 D'Angio CT, Chess PR, Kovacs SJ, Sinkin RA, Phelps DL, Kendig JW, Myers GJ, Reubens L, Ryan RM: Pressure-regulated volume control ventilation vs. synchronized intermittent mandatory ventilation for very low-birth-weight infants: a randomized controlled trial 2. Arch Pediatr Adolesc Med 2005;159:868-875. 
19 Lista G, Colnaghi M, Castoldi F, Condo V, Reali R, Compagnoni G, Mosca F: Impact of targeted-volume ventilation on lung inflammatory response in preterm infants with respiratory distress syndrome (RDS). Pediatr Pulmonol 2004;37:510-514.

20 Nafday SM, Green RS, Lin J, Brion LP, Ochshorn I, Holzman IR: Is there an advantage of using pressure support ventilation with volume guarantee in the initial management of premature infants with respiratory distress syndrome? A pilot study. J Perinatol 2005;25:193-197.

21 Piotrowski A, Bernas S, Fendler W: A randomised trial comparing two synchronised ventilation modes in neonates with respiratory distress (in Polish). Anaesthesiology Intensive Therapy 2007;39:74-79.

-22 Sinha SK, Donn SM, Gavey J, McCarty M: Randomised trial of volume controlled versus time cycled, pressure limited ventilation in preterm infants with respiratory distress syndrome. Arch Dis Child Fetal Neonatal Ed 1997;77:F202-F205.

-23 Singh J, Sinha SK, Clarke P, Byrne S, Donn SM: Mechanical ventilation of very low birth weight infants: is volume or pressure a better target variable? J Pediatr 2006;149:308-313.
24 Keszler M: State of the art in conventional mechanical ventilation. J Perinatol 2009;29: 262-275.

25 Cannon ML, Cornell J, Tripp-Hamel DS, Gentile MA, Hubble CL, Meliones JN, Cheifetz IM: Tidal volumes for ventilated infants should be determined with a pneumotachometer placed at the endotracheal tube. Am J Respir Crit Care Med 2000;162:2109-2112.

-26 Speer CP: Chorioamnionitis, postnatal factors and proinflammatory response in the pathogenetic sequence of bronchopulmonary dysplasia. Neonatology 2009;95:353-361.

27 Grover A, Field D: Volume-targeted ventilation in the neonate: time to change? Arch Dis Child Fetal Neonatal Ed 2008;93:F7-F13.

28 Klingenberg C, Wheeler KI, Owen LS, Kaaresen PI, Davis PG: An international survey of volume-targeted neonatal ventilation. Arch Dis Child Fetal Neonatal Ed DOI:10.1136/adc.2009.181081.

29 Cappelleri JC, Ioannidis JP, Schmid CH, de Ferranti SD, Aubert M, Chalmers TC, Lau J: Large trials vs. meta-analysis of smaller trials: how do their results compare? JAMA 1996;276:1332-1338.

30 LeLorier J, Gregoire G, Benhaddad A, Lapierre J, Derderian F: Discrepancies between meta-analyses and subsequent large randomized, controlled trials. N Engl J Med 1997;337:536-542.
31 Sharma A, Greenough A: Survey of neonatal respiratory support strategies. Acta Paediatr 2007;96:1115-1117.

32 van Kaam AH, Rimensberger PC, Borensztajn D, De Jaegere AP: Ventilation practices in the neonatal intensive care unit: a crosssectional study. J Pediatr 2010;157:767-771.

33 Abubakar KM, Keszler M: Patient-ventilator interactions in new modes of patient-triggered ventilation. Pediatr Pulmonol 2001;32: 71-75.

34 Scopesi F, Calevo MG, Rolfe P, Arioni C, Traggiai C, Risso FM, Serra G: Volume targeted ventilation (volume guarantee) in the weaning phase of premature newborn infants. Pediatr Pulmonol 2007;42:864-870.

35 Erickson SJ, Grauaug A, Gurrin L, Swaminathan M: Hypocarbia in the ventilated preterm infant and its effect on intraventricular haemorrhage and bronchopulmonary dysplasia. J Paediatr Child Health 2002;38:560562.

36 Greisen G, Vannucci RC: Is periventricular leucomalacia a result of hypoxic-ischaemic injury? Hypocapnia and the preterm brain. Biol Neonate 2001;79:194-200.

37 Fritz KI, Ivoria-Papadopoulos M: Mechanisms of injury to the newborn brain. Clin Perinatol 2006;33:573-591. 